\title{
Greek Parents' Opinions and Attitude, Regarding the Physical Exercise of Their Children
}

\author{
Aggeliki Tsapakidou ${ }^{1}$, Eleni Tsompanaki ${ }^{1}$, Konstadinia Dagouli ${ }^{1}$ \& Despoina Zikopoulou ${ }^{1}$ \\ ${ }^{1}$ Department of Early Childhood Education, University of Western Macedonia of Greece, Florina, Greece \\ Correspondence: Aggeliki Tsapakidou, Department of Early Childhood Education, University of Western \\ Macedonia of Greece, 3rd km of the National Florina - Niki Road, P.O. 21, 53100, Florina, Greece. Tel: \\ 30-238-505-5093. E-mail: atsapakid@uowm.gr
}

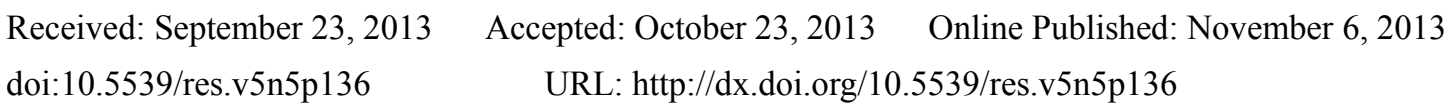

\begin{abstract}
The purpose of this paper is to record, study and analyze the views of parents in Greece, regarding the exercise of their children, the dependence of the parents' opinion with their own participation in sports, the influence of demographic characteristics of parents in relation to their children's training, the factors which encourage and discourage them from participating in athletics and finally the general attitude of parents towards their children's training. In this research there are being involved 230 parents, $32.62 \%$ of which were men and $67.38 \%$ of which were women, from 35 to 45 years old. According to the survey results, the attitude of parents is quite favorable on to encourage their children to sports and the main reasons for this are the health and the fitness of the body, the teamwork and the pleasure - entertainment. In contrast, the most important reasons that make parents discourage them are the lesions and injuries from sports' activities, loss of leisure time and the poor performance at school. In addition, the results showed that the only element that determines, to some extent, the level of the children's physical activity is the mother's profession, while the degree of children's training depends largely on whether parents exercised in the past, and not if they play sports now. Finally, there is a significant correlation between the child's previous exercise and its present activity. It's also being remarked that the more favorable the attitude of the parents towards the sports is, the more the level of the children's taking part in sports increases.
\end{abstract}

Keywords: parents' opinions, physical exercise, children participation in sports

\section{Introduction}

Children's participation in sports activities offers the opportunity to improve their fitness and gain healthy habits that would ideally accompany them later in adulthood. Kids sport, not only is related to the development of physical ability and health but also offers, according to Gallahue (1996), important psychomotor benefits related to psychosocial development, the improvement of self-esteem and confidence, but also to the cognitive and emotional development.

Many researchers have begun efforts to identify the factors which molded the beliefs and attitudes of children towards sport and physical activities and thus affect their participation in them. Parental attitude is a basic influential factor in children's involvement in physical exercises (Australian Sports Commission, 2003; Freedson \& Evenson, 1991; Simonen et al., 2002; Perusse et al., 1989; Godin et al., 1989; Moore \& Lombardi, 1991; Godin \& Shephard, 1986). According to Sallis (et al., 2000), the factors that influence children's participation or non-participation in athletic activities have been clustered in five categories. The first category includes demographic and biological factors associated, according to Loucaides (et al., 2004), with age, ethnicity, gender, socioeconomic status, body mass index of the child's body and also parents' obesity. The second category comprises behavioral factors, which include healthy eating, the desire for physical activity and sedentary habits. The third category includes psychological factors, where as Sallis et al. (2000) and Loucaides et al. (2004) stated are related to self-esteem, self-perception of athletic ability or self-efficacy, and self-concept for body image. In the same category belongs the expectation of the result, the views in extracurricular activities, preferences in specific physical activities, but also the way of addressing barriers to their participation in them. The fourth category includes environmental factors related to climate, the existence of sports equipment in the home and the characteristics of the neighborhood, such as creating appropriately structured spaces for physical activity. Finally, the fifth and final category includes social factors, ie the various social sources of influence, such as peers, 
teachers / coaches, and of course the family (Brustad et al., 2001).

Family is a fundamental form of influence because it represents the most important and primary element of social influence on children, as the majority of their free time before puberty spent within the family (Brustad, 1992; Greendorfer, 1992).

According to Brustad (2010), children through the family 'receive their initial exposure to many different types of physical activity. Almost invariably, children engage in exploratory play and learn to walk, run, jump, climb, and ride a bike in the presence of parents and/or siblings and all of this early exposure to physical activity typically takes place before children have become involved in structured physical activity experiences, such as school-based physical education or organized sport programs' (p. 3).

Welk кal Schaben, (2004), support that parents can be seen as 'guardians' of children's physical activity, and allow or restrict the opportunities for children to participate in physical activities.

According to Taylor, Baranowski and Sallis (1994), family members, especially parents can play a very important role in shaping appropriate children's beliefs toward sports. The qualitative and quantitative participation of the parent in the evolutionary process of the child, within which falls the preoccupation with sports activities, is known in the literature as 'parental support' and is a very popular subject of research the last years. There are many types of parental influence that appear in literature and mechanisms are still being studied in depth but are nevertheless barely perceptible (Prochaska et al., 2002).

According to Baranowski (1997), parents can influence children's behaviours towards sports through different mechanisms such as genetics, direct modeling, to reward desired behaviors, punishment or ignoring unwanted, create or eliminate obstacles, providing resources for the execution of these behaviors and that appropriate procedures parenting would help to develop self-control skills (Stewart et al., 2003). According to Bustad's (2010) survey, four of the above mechanisms have the most important forms. The first concerns the extent to which parents allow and provide opportunities for their children to participate in sports. As explained by Mackett and Paskins (2008), children participate in more physical activities outside the home rather than in it, but they are still not able to decide autonomously about outdoor play. The first experiences in physical activities affect the degree of attraction of children to them, which will be an incentive for their future involvement. As children mature, parents continue to influence children on physical activities, as it is depended on parents' involvement in buying sports equipment, enrolling their children to sports academies. Another parental influence is related to parental support and encouragement. To do so, they need to firstly deeply understand the value of physical activity. In a survey of Bauer and Nelson (2008), it was found a significant correlation between high levels of participation in sports activities and children (boys and girls) whose parents encourage them to participate in sports, over a five years period of time. This finding shows us that the authoritative parental support contributes significantly to the development of appropriate incentives for children to physical activity. A third important form of influence consists of role modeling practices or the representative identification of children with physical activities (Bandura, 1986). Essentially, this form has to do with the child's observation in attitudes, opinions and beliefs of parents towards sports. Nevertheless, parents are not a role model only affecting their children's behavior towards athletic activities, but also their attitudes and their feelings on particular likes and dislikes in relation to physical activity. Thus, we conclude that parental modeling includes behaviors and emotional reactions, which are transferred to the child, mainly through shared experience in sport and through practical behavior of the parents themselves. As regards the percentage of influence has been shown by Brustad, (1996), that the motivation of children to physical activity is more influenced by the positive views of parents rather than the rate of physical activity performed by the parents themselves. On the other hand, researchers at Framingham children's study looked at the behavior of children in physical activities aged 4-7 years and their parents and found that children of two "sports active" parents had 5.8 times more chances to be the same "active" than were the children of both "sports inactive 'parents. Children from families with an 'active' and one 'inactive' parents were still 3.5 times more likely to be "active sports" by children in families with two "inactive" parents (Moore et, al., 1991).

The fourth form of parental influence refers to the shaping of children's perceptions about their abilities and skills in physical activities. The feeling of competence is an important prerequisite for intrinsic motivation in physical activities. As children have no previous records of the values and benefits of sport, they tend to recall what they hear from their parents. Their beliefs are highly influenced by their parents' beliefs as children have no previous experience (Stipek et al., 1992). Parents provide feedback and encouragement in activities that are sure success is anticipated. Parental expectations influence the opportunities given to their children.

To date, most research on children's physical activity has focused on the mechanism of direct modeling, but also 
in parenting beliefs, and particularly in the parental perceptions of their children's ability. Much interest was observed by the researchers about whether the father or the mother is the one that most affects the child in terms of athletic activity. Father and mother may not have similar appraisals of their child's abilities and it is likely that one parent might be more influential than the other. Snyder and Spreitzer (2001) in their research in 500 families, found that father's role is very important and it is highly related to the degree a child (boy or girl) participates in related physical activities. From another perspective, these researchers showed that mother's importance on the interest on physical activities is of course smaller. So it seems when the father is actively involved in sports and exercise, is clearly increases the chances of the child having the interest to be involved in exercise following the model of his father. According to Freedson's kal Evenson's (1991) results, 73\% showed similarity in the choice of activity between mother and child, while $67 \%$ between father and child.

More researches reached the same conclusions and argued that mothers are the ones who typically dwell in the education of their children during childhood and the period before puberty. Thus, mothers' perceptions may be particularly important in shaping the beliefs of the child, even in traditionally masculine sports (Jacobs \& Eccles, 1992; Eccles et al., 1983; McGrath \& Repetti, 2000).

Unlike the researches that outpoint a positive correlation between levels of physical activity of parents and their children, Anderssen et al., (2006) conducted a long-term research and found a non-existing correlation between the physical activity of parents and their children. Indeed, the results of this investigation showed that physical activity of parents is not transferred to their children to the extent that is often assumed. The same conclusions are reached by Bangdiwala (1993), DiLorenzo et al., (1998), Godin et al., (1986), Trost et al., (1997), Zakarian et al., (1994), Anderssen et al., 2006, showing little or minimal correlation between physical activity of parents and children.

Six research questions were formed in order to shape the structure of this research: 1 . What are parents' views and beliefs on the importance of sports to children between 6 and 10 years old? 2. What are the main reasons that lead parents to encourage their children to participate in physical activities? 3 . What are the factors that discourage them from participating in athletics? 4. How does the demographic characteristics of the parents (occupation, education and gender) affect the level of physical activity of their children and their views about sports? 5. What is the degree of association between the level of fitness of children and the beliefs of the parents, with the fitness level of the parents 6 . Is the general attitude of parents towards athletics related to the degree of fitness of their children?

\section{Design and Methods}

\subsection{Sample}

In the present research, a quantitative survey, using a structured written questionnaire was addressed to 203 parents between 35-45 years who have children who attend primary school, aged 6-10 years. Of the parents who attended the $32.62 \%$ were male and $67.38 \%$ female. Subjects were collected from primary schools located in Thessaloniki.

The questionnaires were distributed to a random sample, and then the coding of the data collected started as well as statistical processing using the statistical program SPSS. In order to test the effect of the data collection strategies, the statistical technique of one- way analysis of variance (ANOVA) was applied. The questionnaire was written in order to cover the maximum possible extent of the research questions, and consisted of four parts.

The first part included close-ended questions for the collection of demographic elements of parents regarding the educational level and their profession. Furthermore, parents gave information about their children, relating to gender, age, weight, and height. Subsequently, the second part contained seven questions related to the sporting activity of both the parent and the child. Each of these questions leaves free the parent to complete the kind of sport he/she is involved, but it is a close-ended question with respect to the frequency of doing sports. In addition, parents are asked to indicate whether they themselves choose the sport for their child or not.

The third part of the questionnaire included 18 close-ended questions using Likert scale. These questions relate to the views of parents about sports, its importance for the life of their child and whether they encourage their children or not in order to participate in it.

Finally, the fourth part of the questionnaire invites parents to choose from two lists, the five most important reasons to deal with their child's sports activities and the five most important reasons not to deal.

The validity of the data collected was evaluated by calculating the coefficient Crombach a. This is the coefficient that values ranges from zero to one (in some cases takes negative values) and expresses the validity of the data according to the calculation. Values above 0.6 reflect perfectly valid data. In this study, the coefficient was 0.901 , 
which expresses the validity of the data collected.

For the balance of the questionnaire, a pilot questionnaire has been conducted, supplementing a small sample of participants in order to evaluate the validity and reliability, but also making clarifications and corrections.

\section{Results}

Originally, presented are the demographics elements of parents who participated in the survey. Regarding occupation, the father is the most common private employee, followed by the public official and the freelancer.

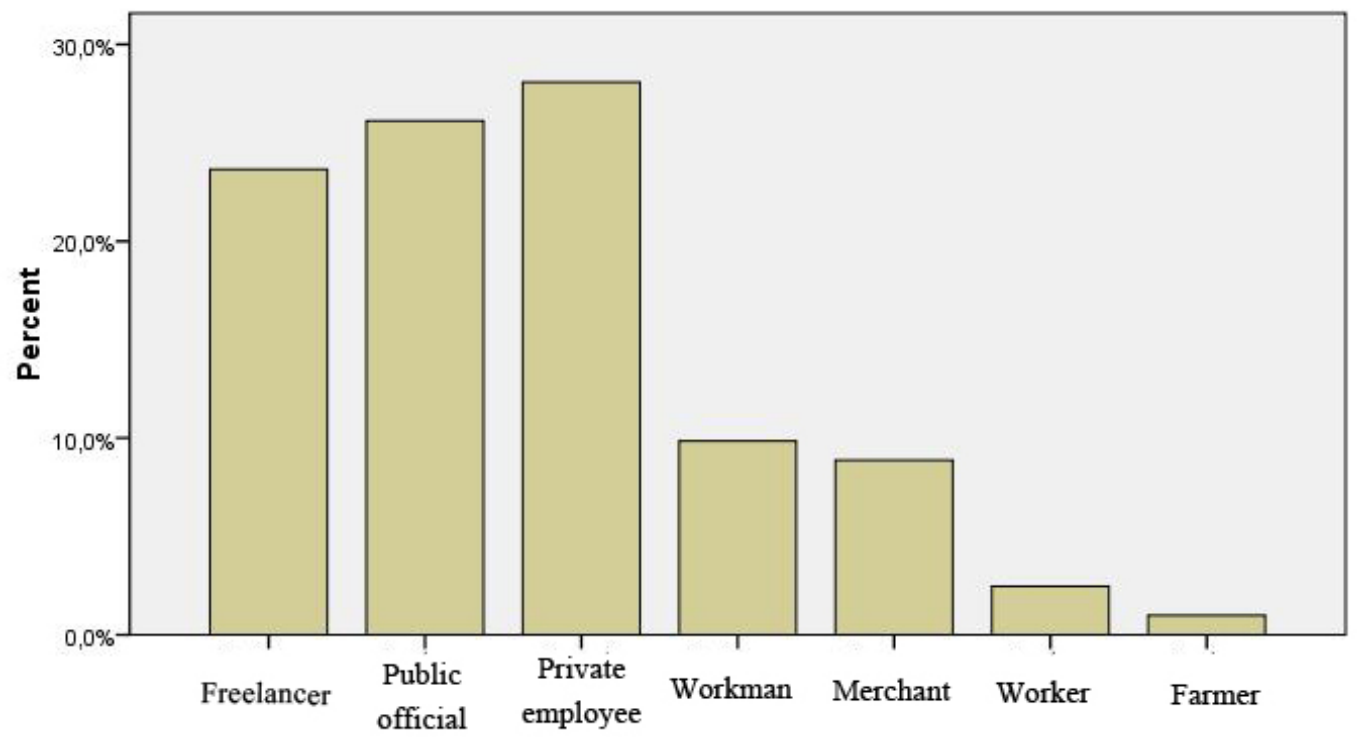

Figure 1. Father's occupation

As far as it concerns mothers, most are public servants, slightly fewer private servants and follow those running a household.

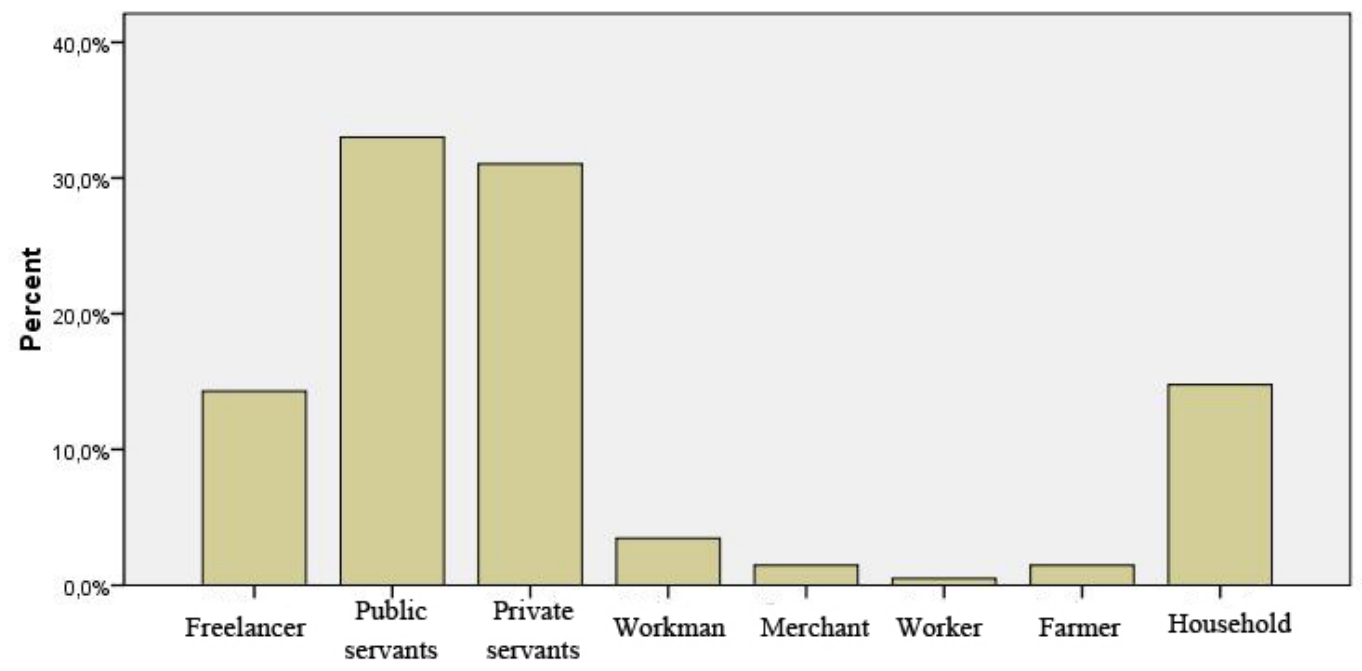

Figure 2. Mather's occupation

The level of parents' education, it seems that fathers, $32 \%$, are graduates of highest education institutions, and $31 \%$ are of secondary school graduates. Fewer are those who are graduates of higher education institutions or have completed postgraduate studies. 


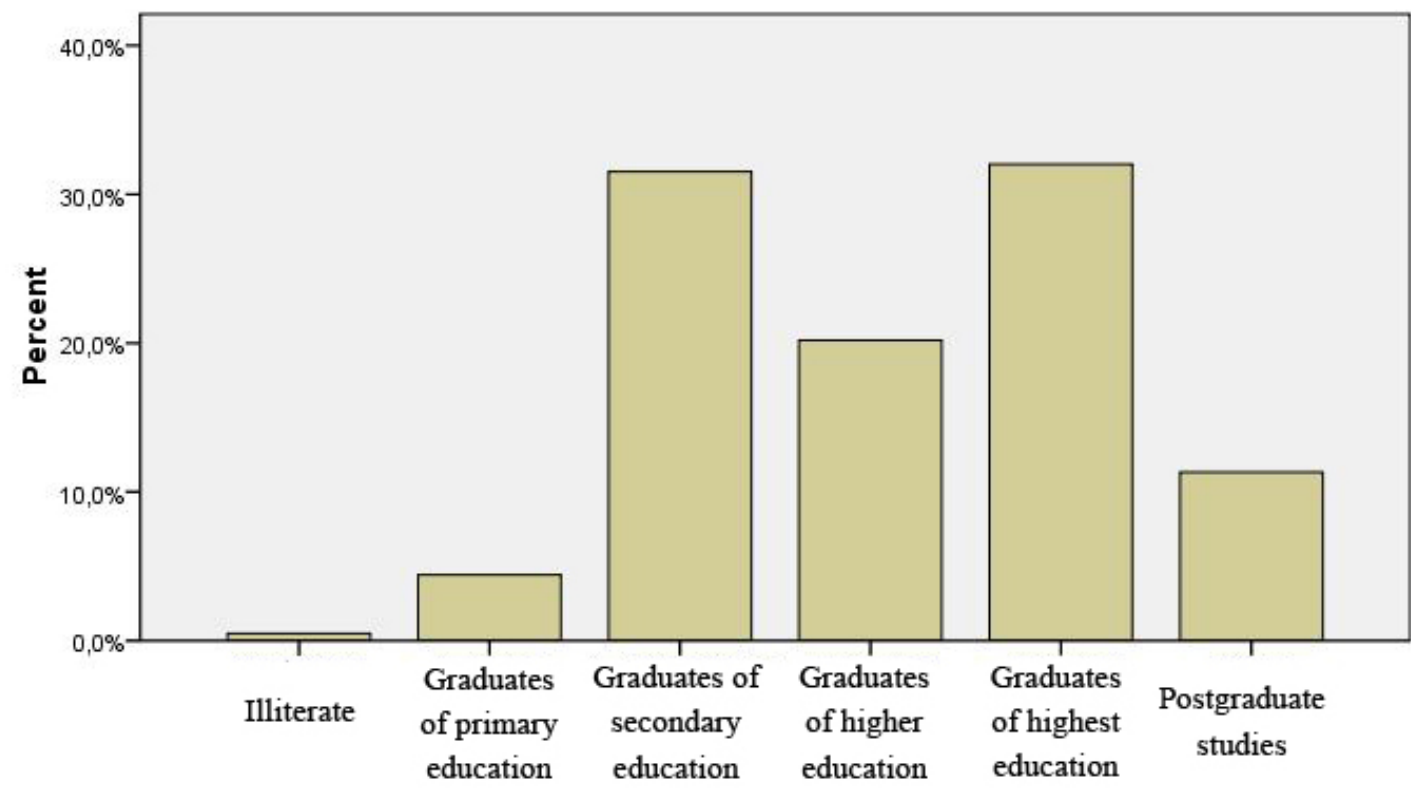

Figure 3. Father's education

A similar picture appears for the mother, with slightly elevated rates of those who are graduates of highest and secondary education and slightly lower rates for graduates of higher and postgraduate education.

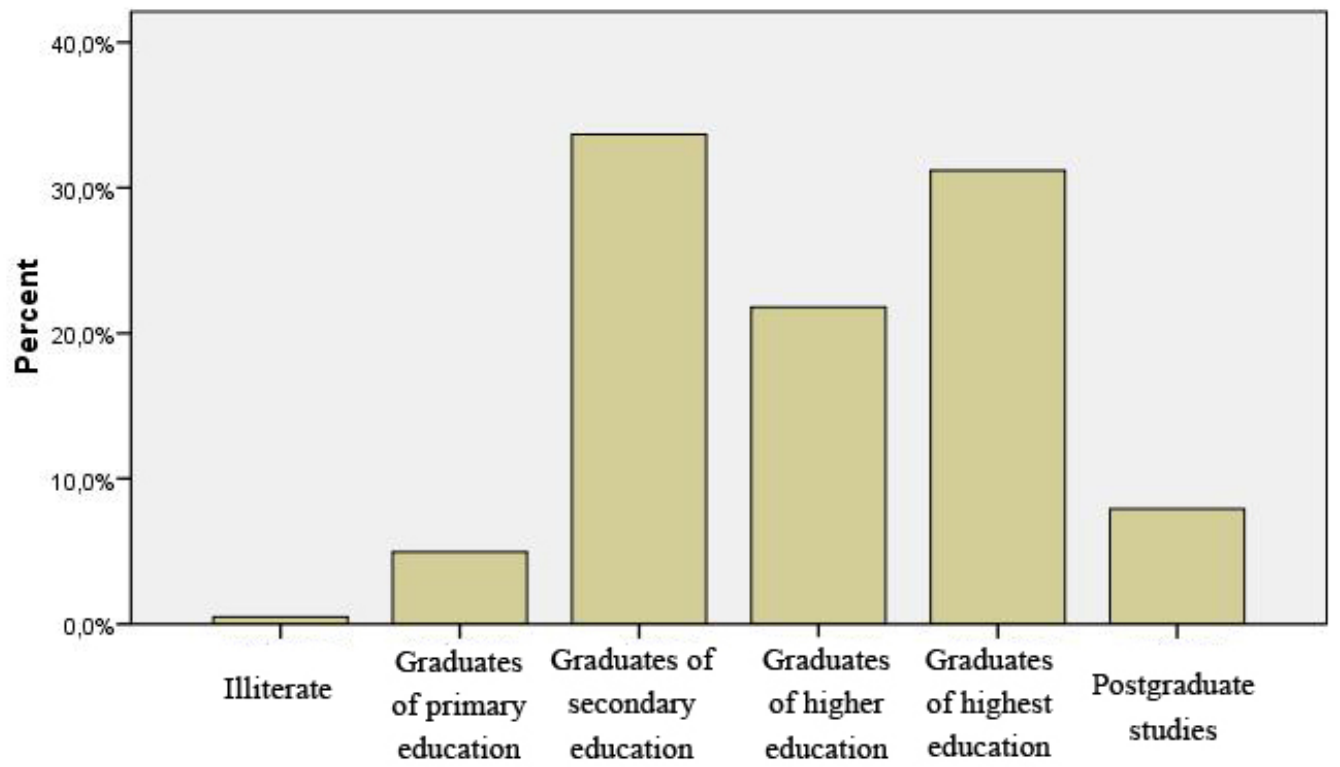

Figure 4. Mather's education

As far as it concerns the participants' children, elements concerning their gender, age, weight and height were collected. Concerning the gender, the results showed, as seen in Table 5, that there is an equal distribution in boys and girls. 
Table 1. Elements of children's gender

\begin{tabular}{lccc}
\hline & Gender of the first child (200) & Gender of the second child (126) & Gender of the third child (23) \\
\hline Boys & $50,7 \%$ & $29,1 \%$ & $7,9 \%$ \\
Girls & $47,8 \%$ & $33 \%$ & $3,4 \%$ \\
\hline
\end{tabular}

Initially, parents were asked to respond with respect to whether they exercised in the past. As shown in the table below, 30\% answered 'I exercise often' and 25\% 'sometimes'. About 15\% of respondents have not exercised ever. Indeed, as shown in the results, the most popular sports are aerobics and exercises within gyms.

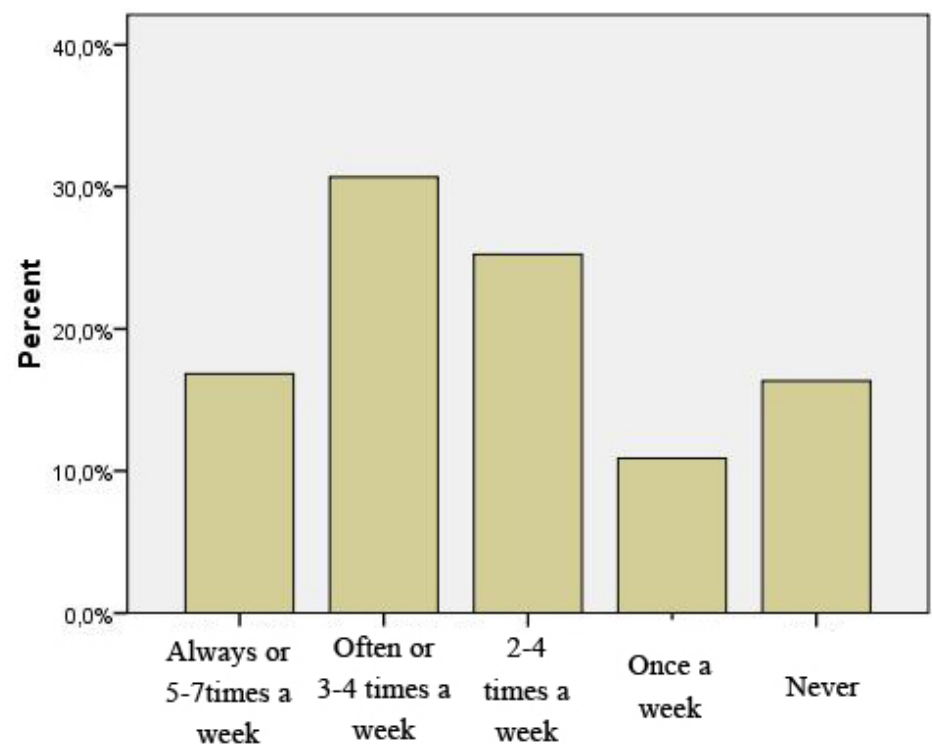

Figure 5. Did you exercised in the past?

Particularly interesting is how this picture changes when parents expressed themselves about herein. As shown in the table $7,47 \%$ of the respondents say that at the moment they are not working out at all, while $20 \%$ do not play sports, only rarely.

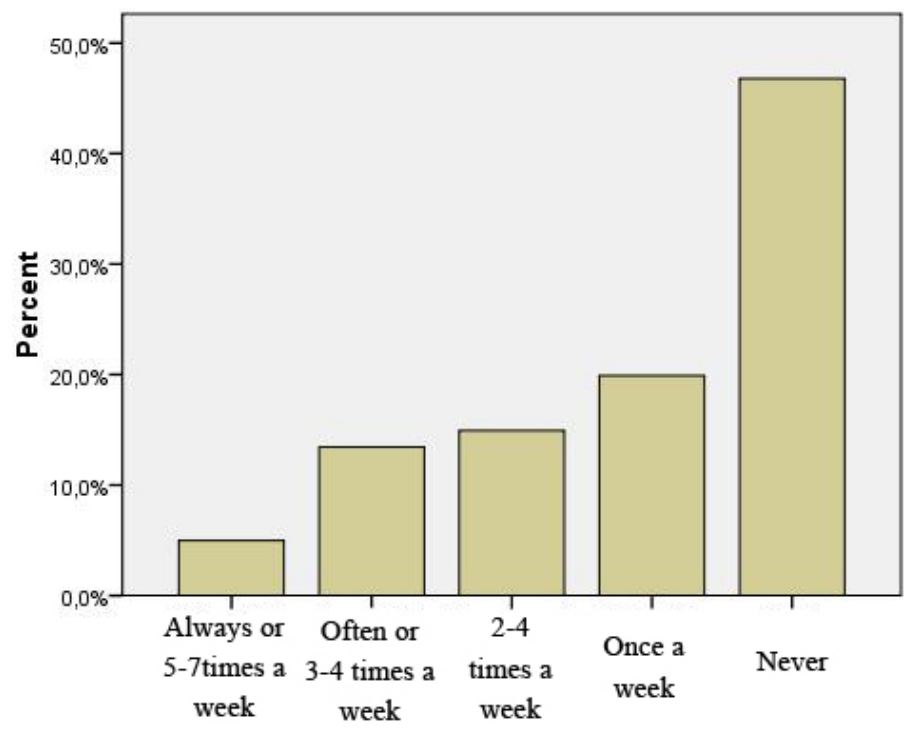

Figure 6. Do you exercise now?

Regarding whether respondents' spouses exercised in the past, 35\% of cases, admitted that their wife/husband did not exercise ever in the past, while $25 \%$ frequently exercised. Indeed, according to the results, the most 
commonly occurring sports were football (11.3\%) exercising in the gym (9.9\%) and basketball.

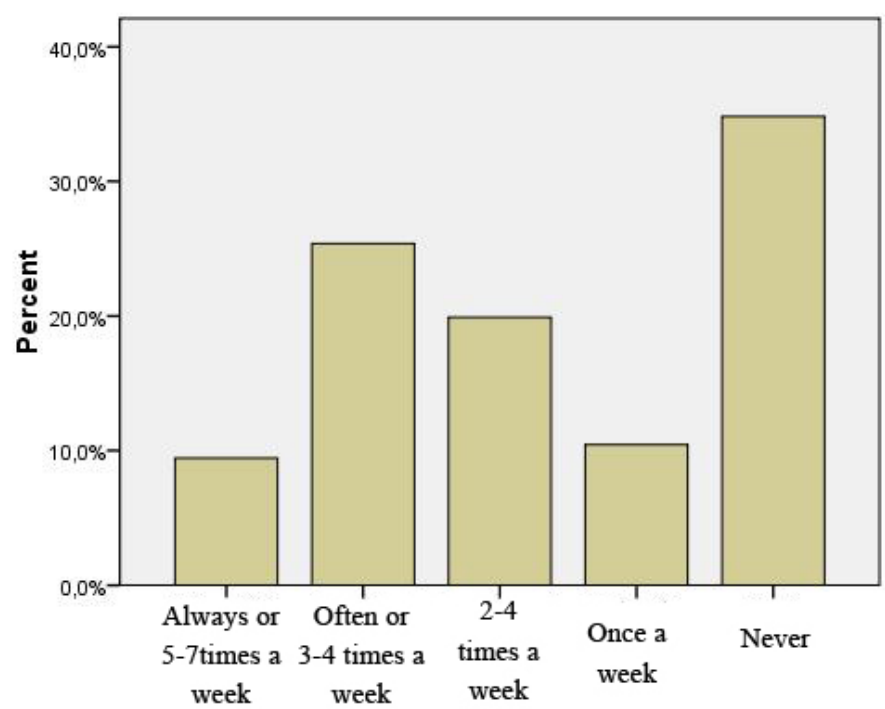

Figure 7. Did your wife/husband exercised in the past?

And in this case, the difference in the degree of fitness in the present than in the past is very big. More specifically, we see that now $56 \%$ of the respondents' spouses have not played sports ever, and $20 \%$ play sports just 2 times a week or rare. Overall, we can say that there is a tendency for parents to greatly reduce their sporting activity in relation to the past.

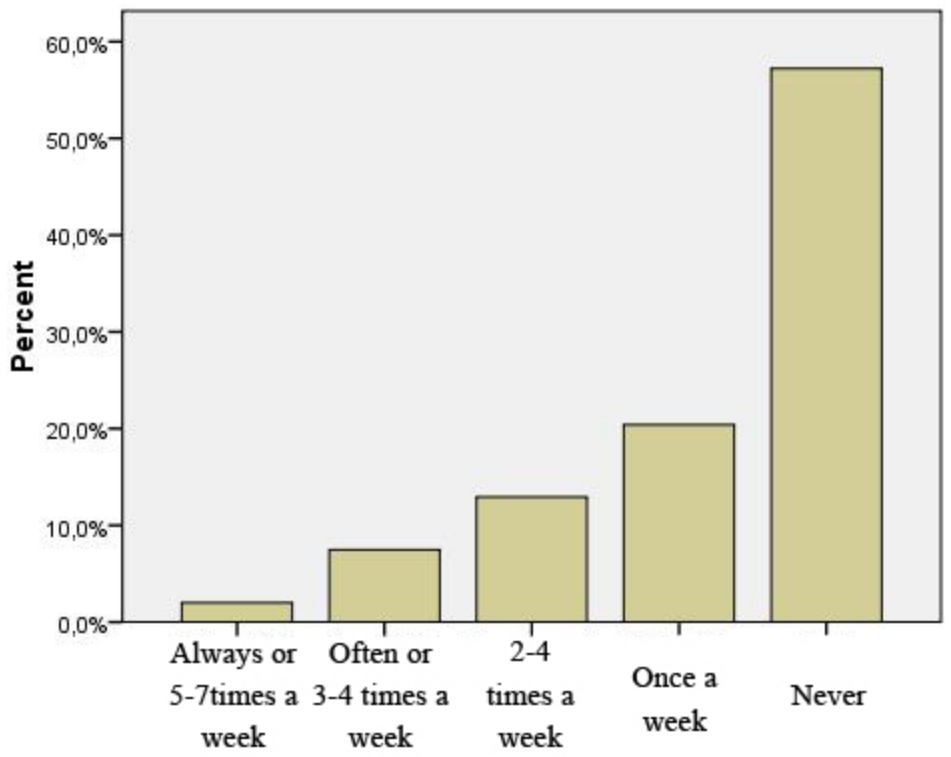

Figure 8. Does your wife/husband exercise now?

Subsequently, respondents were asked about the extent of sporting activity of their children. As shown in the table below, $38 \%$ of children in the past exercise modestly ( 2 times a week), while $28 \%$ frequently and $26 \%$ have no physical activity at all. The sports that assemble larger percentages are dancing (25.1\%), swimming (26.1\%), soccer $(15.3 \%)$ and martial arts $(11.3 \%)$. 


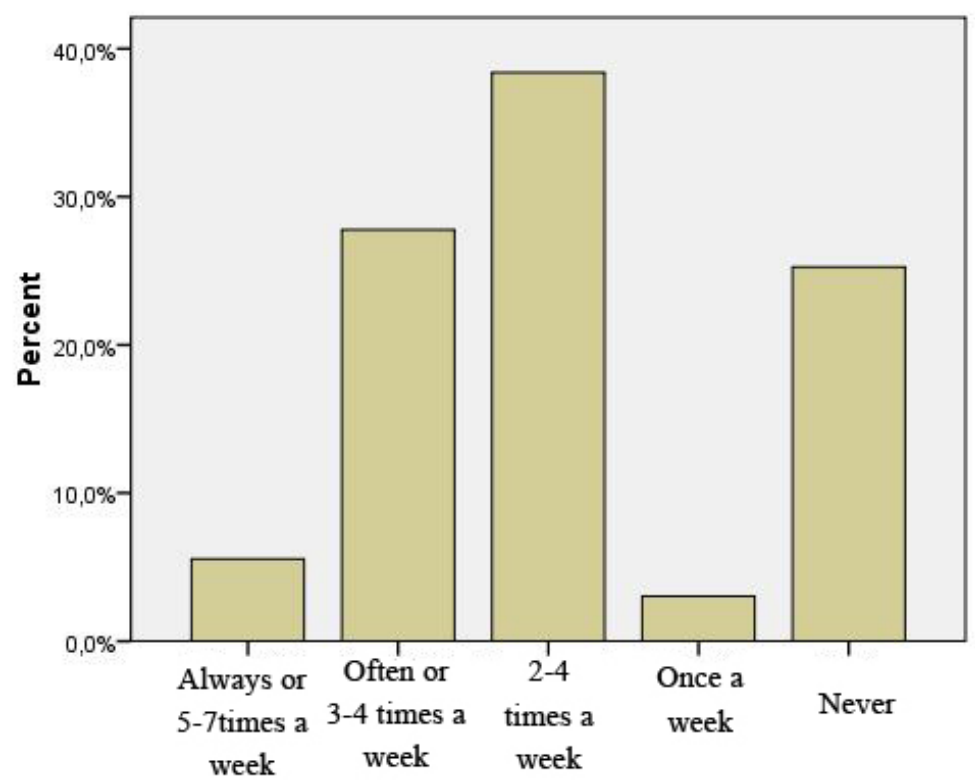

Figure 9. Did your child exercised in the past?

Respectively, for fitness levels of children today, the picture is similar, with no significant changes. Children exercise sometimes ( 2 times a week) by $38 \%$, often ( $3-4$ times a week) in $32 \%$, and never $20 \%$. The sports mentioned by parents and in this case are dancing (22.2\%), swimming (20.7\%), soccer (16.7\%) and martial arts $(12.8 \%)$.

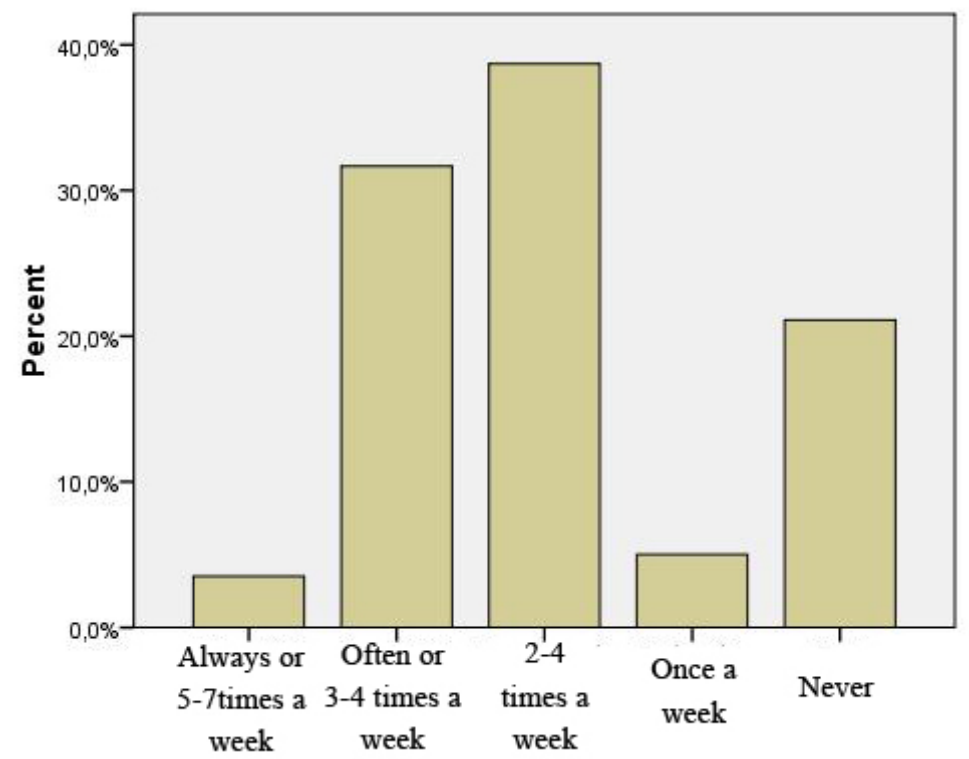

Figure 10. Does your child exercise now?

As seen from the graph 1, the choice of sport is a decision of the child, as reported by at least $82.07 \%$ of the respondents, and for only $17.93 \%$ of cases it is the parents who themselves choose the sport of their child. 


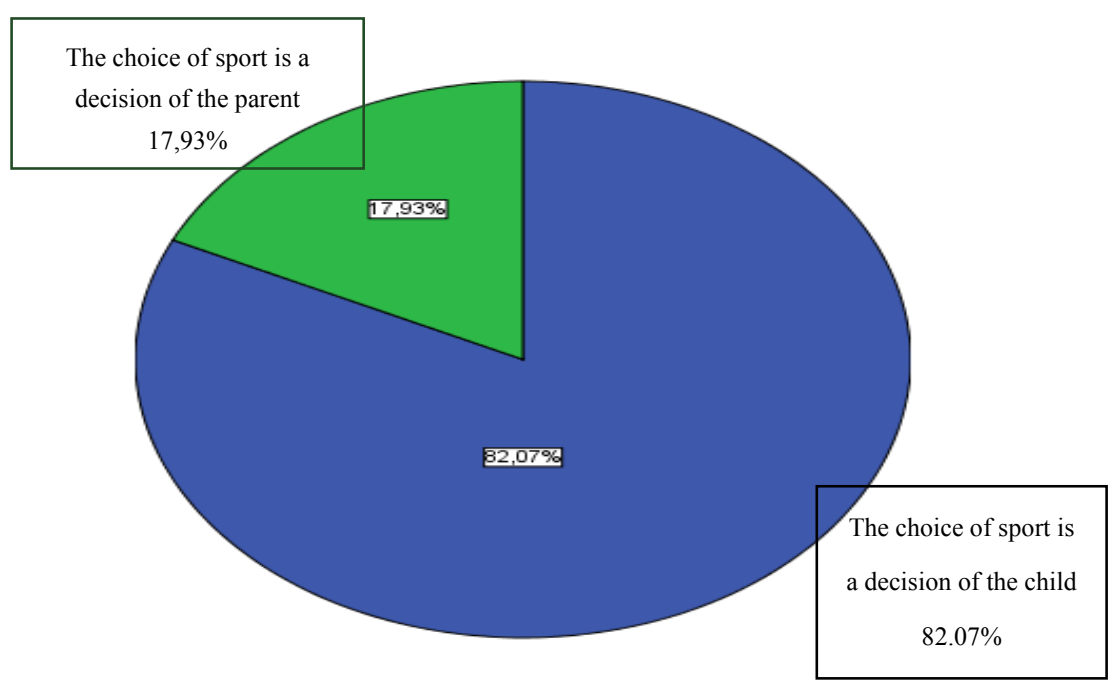

Figure 11. Is the choice of sport a decision of the child or the parent?

Regarding the wider stance of the parents, a total score was calculated based on the scale of attitudes, the characteristics of which also appear in the following table. The game can take values from 1 to 5 . Prices from 3 and above correspond to relatively favorable attitude of parents towards the sport for their children. As shown in Table 12, the average value of the score is 3.83 , which means that parents have a quite favorable attitude towards sport for their children. The standard deviation is 0.537 , thus, there are no major deviations from the mean. The maximum value observed is 4.61 .

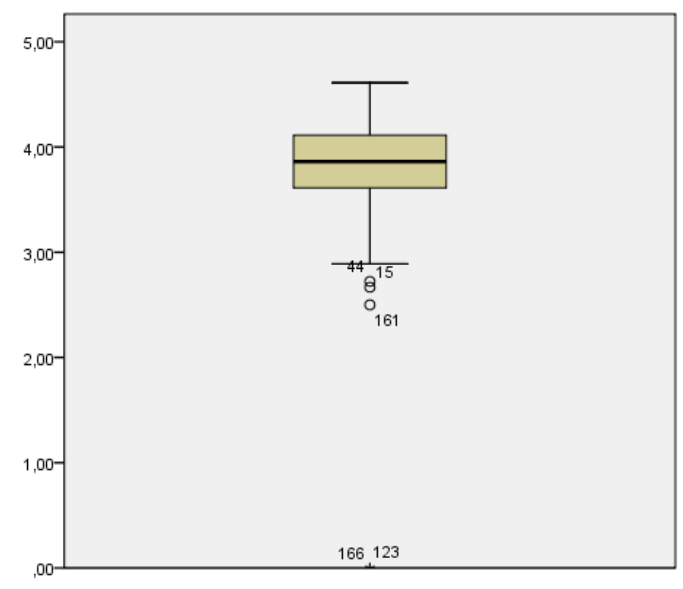

Figure 12. The wider stance of the parents

The following two tables present the main reasons which may lead parents either to encourage their children to work out, either discouraging them. The main reasons that make parents encourage their children are health $(90.3 \%)$, the body fitness (76\%), teamwork $(70.9 \%)$, and pleasure - entertainment $(67.9 \%)$.

Table 2a. Reasons which may lead parents to encourage their children to exercise

\begin{tabular}{lcc}
\hline & No & Yes \\
\hline Body fitness & $24,0 \%$ & $76,0 \%$ \\
Aesthetically a beautiful body & $85,7 \%$ & $14,3 \%$ \\
Health & $9,7 \%$ & $90,3 \%$ \\
Pleasure - entertainment & $32,1 \%$ & $67,9 \%$ \\
Skills/Talent & $90,3 \%$ & $9,7 \%$ \\
Hobby & $84,2 \%$ & $15,8 \%$ \\
Championship & $96,9 \%$ & $3,1 \%$ \\
\hline
\end{tabular}


Table 2b. Reasons which may lead parents to encourage their children to exercise

\begin{tabular}{lcc}
\hline & No & Yes \\
\hline Healthy Life & $64,8 \%$ & $35,2 \%$ \\
Teamwork & $29,1 \%$ & $70,9 \%$ \\
Favourite pastime & $87,2 \%$ & $12,8 \%$ \\
Fame & $99,5 \%$ &, $5 \%$ \\
Avoiding of obesity & $84,7 \%$ & $15,3 \%$ \\
Avoiding bad habits & $53,6 \%$ & $46,4 \%$ \\
Child's desire & $42,3 \%$ & $57,7 \%$ \\
\hline
\end{tabular}

Respectively, according to the following table, the most important reasons that lead parents to discourage their children from sports is that it does not wish their child to participate in percentage (68.4\%), injuries (65.3\%), loss of leisure time (55.6\%) and poor performance at school (44.9\%).

Table 3. Reasons which may lead parents to encourage their children to discourage their children from sports

\begin{tabular}{lcc}
\hline & No & Yes \\
\hline Poor performance at school & $55,1 \%$ & $44,9 \%$ \\
Injuries & $34,7 \%$ & $65,3 \%$ \\
Waste of time & $94,9 \%$ & $5,1 \%$ \\
Eating limitation & $86,2 \%$ & $13,8 \%$ \\
My child is not physically skilful & $88,3 \%$ & $11,7 \%$ \\
My child is obese & $93,9 \%$ & $6,1 \%$ \\
My child is a girl & $98,5 \%$ & $1,5 \%$ \\
Loss of the childhood & $87,2 \%$ & $12,8 \%$ \\
Loss of leisure time & $44,4 \%$ & $55,6 \%$ \\
Character weakness & $88,3 \%$ & $11,7 \%$ \\
Avoidance of obsession & $75,0 \%$ & $25,0 \%$ \\
My child does not wish to participate & $31,6 \%$ & $68,4 \%$ \\
Cost of sports & $70,9 \%$ & $29,1 \%$ \\
\hline
\end{tabular}

Then the correlation of the level of fitness of children and the attitude of the parents was examined with the demographic characteristics of the parents. The correlation coefficient (Pearson) shows no statistically significant relationship between the age of the parent with these parameters.

Table 4. Correlation of the level of fitness of children and the attitude of the parents with the age of the parent

\begin{tabular}{lcc}
\hline & & Age of the parent \\
\hline & Pearson Correlation & $-0,033$ \\
Did your child exercised in the past? & Sig. (2-tailed) & 0,649 \\
& N & 0,001 \\
Does your child exercise now? & Pearson Correlation & 0,987 \\
& Sig. (2-tailed) & 199 \\
The wider stance of the parents & N & 0,049 \\
& Searson Correlation & 0,490 \\
\hline
\end{tabular}

Afterwards, the degree of association between the level of fitness of children and the attitude of the parents was examined with the profession of the father. Test was performed by one - way Anova analysis and according to the results, there is no statistically significant correlation with the occupation of the father. 
Table 5. Correlation of the level of fitness of children and the attitude of the parents with the occupation of the father

\begin{tabular}{lcc}
\hline & F & Sig. \\
\hline Did your child exercised in the past? & 1,435 & 0,203 \\
Does your child exercise now? & 1,602 & 0,149 \\
Stance of the parents &, 228 & 0,967 \\
\hline
\end{tabular}

Subsequently, we studied the correlation of the level of fitness of children and the attitude of the parents according to the mother's occupation. The degree of fitness of children both in the past and present, associated with the mother's occupation $(\mathrm{p}=0.008$ and 0.031 respectively). More specifically, more involved in sport are children of professionals (scientists and technicians) and traders.

Table 6. Correlation of the level of fitness of children and the attitude of the parents with the occupation of the mother

\begin{tabular}{lcc}
\hline & F & Sig. \\
\hline Did your child exercised in the past? & 2,820 & 0,008 \\
Does your child exercise now? & 2,259 & 0,031 \\
The wider stance of the parents & 1,664 & 0,120 \\
\hline
\end{tabular}

Then we examined the correlation of the level of fitness of children and the attitude of parents to the education of the father and mother respectively, where in both cases there was no significant correlation.

Subsequently, we studied the correlation of the level of fitness of children and the attitude of the parents, according to the fitness level of the parents. Initially, a verification on whether the parents were exercising in the past was made. Test was performed by one - way Anova analysis and as observed the degree of fitness of children in the past but also the wider stance of parents is associated with the fact that parents were exercising in the past ( $\mathrm{p}=0.016$ and 0.001 respectively). More specifically, more involved in sports are children of parents who exercised in the past 5-7 times a week, and as expected, the parents themselves have a more favorable attitude towards sports.

Table 7. Correlation of the level of fitness of children and the attitude of the parents associated to the fitness level of the parents in the past

\begin{tabular}{lcc}
\hline & F & Sig. \\
\hline Did your child exercised in the past? & 3,130 & 0,016 \\
Does your child exercise now? &, 930 & 0,448 \\
The wider stance of the parents & 4,759 & 0,001 \\
\hline
\end{tabular}

Accordingly, it became necessary to check on whether the variables under consideration and of whether the parent is now regularly exercising are affected. As demonstrated in the analysis, none of the three dependent variables are statistically significant, associated with whether parents play sports now.

Table 8. Correlation of the level of fitness of children and the attitude of the parents associated with whether parents play sports now

\begin{tabular}{lcc}
\hline & F & Sig. \\
\hline Did your child exercised in the past? & 2,101 &, 082 \\
Does your child exercise now? & 1,140 &, 339 \\
The wider stance of the parents & 1,256 &, 289 \\
\hline
\end{tabular}

Finally, a control check was made on whether the degree of fitness of children affected by the wider stance of the 
parent towards sport. Test was performed by univariate analysis one - way Anova. As shown there is a significant correlation at 0.05 if they were exercising with their child in the past, and whether they regularly exercise now ( $p$ $=0.02$ and 0.00 respectively). More specifically, the more favorable is the attitude of parents towards the sport, the greater the level of sport for children.

Table 9. Correlation of the level of fitness of children to the wider stance of the parent towards sport

\begin{tabular}{lcc}
\hline & & The wider stance of the parents \\
\hline & Pearson Correlation &,$- 224 * *$ \\
Did your child exercised in the past? & Sig. (2-tailed) &, 002 \\
& $\mathrm{~N}$ & 197 \\
Does your child exercise now? & Pearson Correlation &,$- 327^{* *}$ \\
& Sig. (2-tailed) &, 000 \\
& $\mathrm{~N}$ & 198 \\
\hline
\end{tabular}

\section{Discussion}

The purpose of this research was to study and record the views of parents in sport and discuss the key role they play in the involvement or not of their children in sporting activities. Six research questions shaped this research and are analysed below, based on the results recorded.

The first research question concerned the level at which the views and beliefs of parents towards their children's sports range. The analysis of the results showed that the views of parents are quite favorable on to encourage their children to sport. Parents do not act as role models only due to their behavior towards sports, but for their likes and dislikes in relation to physical activity. Parental modeling includes behaviors and emotional reactions, which are transferred to the child, mainly through shared experience in sport and through practical behavior of the parents themselves. It seems that the motivation of children to physical activity is more influenced by the positive views of parents rather than the rate of physical activity performed by the parents themselves (Brustad, 1996, 2010).

The second research question concerned the major reasons that motivate parents to encourage their children to engage in sports. The results showed that these reasons include health, body training, teamwork and pleasure entertainment. It seems that what does not play an important role to parents, is an aesthetically beautiful body, the championships, being popular, or the avoidance of obesity and employment.

The third research question focused on the reasons that motivate parents to discourage their children from sports. According to the results, the most important factors are child's lack of desire to be involved in sports, injuries, loss of free time and poor performance in school. Instead, as demonstrated by the analysis, it plays no role to parents the gender, body weight, the loss of free time, the weakness of nature, dietary restrictions, the skill of the child or the possible loss of childhood.

The next research question examined whether the level of physical activity of children and the views of parents are determined by the demographic characteristics. As demonstrated in the analysis, the only factor which determines, to a certain extent, the level of physical activity of children, is the profession of the mother (Freedson \& Evenson, 1991; Jacobs \& Eccles, 1992; Eccles et al., 1983; McGrath \& Repetti, 2000). Moreover, mother is an influential figure as she spends more time with her child from early childhood to adolescence. It is the mother who usually deals with the education of the child, so she conveys perceptions, beliefs and views on sport and thus, affects the child to a greater extent than the father.

The fifth research question, examined the degree of association between the level of fitness of children and the beliefs of the parents, with the fitness level of the parents. Originally, an assessment was made on whether a parent was exercising in the past. According to the results of the analysis, the degree of fitness of children in the past was also examined and also the wider stance of parents associated with the whether they were exercising in the past. More specifically, as demonstrated by the analysis more involved in sports are children whose parents were exercising in the past "always" or "5-7 times a week". Thus, parents themselves are the ones who have a more favorable attitude to the sport, as expected (Moore et al., 1991). Accordingly, it became necessary to examine on whether the affected variables under consideration are determined on whether the parent is now regular exercising. As demonstrated in the analysis, none of the three dependent variables were statistically significant with whether parents play sports now. 
The results of this study showed that the degree of fitness of children depends mainly on whether parents were exercising previously and not on whether they exercise now (Of course at this point it is worth to stress that it is likely that this result is due to the fact that the level of fitness of parents is now very limited, either due to lack of time or mood, either due to increased liabilities).

The last research question concerned with the extent on which the degree of fitness of children depends on the general views of the parent towards sports. As shown in the results, there is a significant association with whether a child was exercising in the past, and whether he/she exercises regularly now. More specifically, the more favorable is the attitude of parents towards the sport, the greater the level of fitness of children (Taylor et al., 1994; Baranowski, 1997). It seems that there is a positive correlation between levels of physical activity of parents and their children. (Freedson \& Evenson, 1991; Simonen et al., 2002; Perusse et al., 1989; Godin et al., 1989; Moore \& Lombardi, 1991; Godin \& Shephard, 1986).

\section{Conclusion}

This research focused on Greek parents and their attitudes towards their children's involvement in sports or physical activities in general. It was evident how important the involvement of parents is, in shaping the beliefs, opinions and feelings of children towards sports. The results revealed that parents, particularly those who exercised in the past, compel their children to sport more than those who have never been involved with sports. A reasonable result, as "active parents" that have favorable views and beliefs towards sport, understand the value of sport and transfer it to their child who is influenced and follows his/her parents. It is obvious that parents are the most important factors of socialization for children and their behavior towards physical activity is a key factor for the standard exercise for children. Notwithstanding, the smaller the child is involved with sports, the more likely it is to follow this behavior and understand that sport for him/her would be "a way of life for a life."

\section{References}

Anderssen, N., Wold, B., \& Torsheim, T. (2006). Are parental health habits transmitted to their children? An eight year longitudinal study of physical activity in adolescents and their parents. Journal of adolescence, 29(4), 513-524. http://dx.doi.org/10.1016/j.adolescence.2005.05.011

Australian Sports Commission. (2003). How parents support their child's physical activity? Retrieved from http://www.curriculumsupport.education.nsw.gov.au/secondary/pdhpe/assets/pdf/pa_021.pdf

Bandura, A. (1986). Social foundations of thought and action: A social cognitive theory. Englewood Cliffs, NJ: Prentice Hall.

Bangdiwala, S. I. (1993). Parental influences on childhood fitness and activity patterns. Research Quarterly for Exercise \& Sport, 64, 249-255. http://dx.doi.org/10.1080/02701367.1993.10608809

Baranowski, T. (1997). Families and health actions. In D. S. Gochman (Ed.), Handbook of health behavior research I: personal and social determinants (pp. 179-206). New York: Plenum Press.

Bauer, K. W., Nelson, M. C., Boutelle, K. N., \& Neumark-Sztainer, D. (2008). Parental influences on adolescents' physical activity and sedentary behavior: Longitudinal findings from Project EAT-II. International Journal of Behavioral Nutrition and Physical Activity, 5(12), 1-7.

Brustad, R. J. (1992). Integrating socialization influences into the study of children's motivation in sport. Journal of Sport \& Exercise Psychology, 14, 59-77.

Brustad, R. J. (1996). Attraction to physical activity in urban schoolchildren: Parental socialization and gender

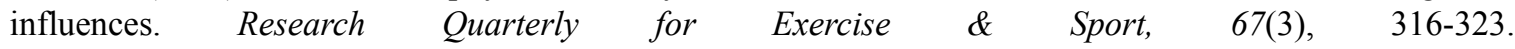
http://dx.doi.org/10.1080/02701367.1996.10607959

Brustad, R. J., \& Smith, A. L. (2001). Youth in sport: Phychological considerations. In R. N. Singer, H. A. Hausenblas, \& C. M. Janelle (Eds.), Handbook of Sport Psychology (2nd ed., pp. 604-635). New York: Wiley.

Brustad, R. J., (2010). The role of family in promoting physical activity. President's Council on Physical Fitness and Sports Washington, D.C. (Series 10, No 3).

Davison, K. K., Cutting, T. M., \& Birch, L. L. (2003). Parents' activity-related parenting practices predict girls' physical activity. Medicine \& Science in Sports \& Exercise, 35(9), 1589-95.

DiLorenzo, T. M., Stuckey-Ropp, J. S., Van Der Wal, J. S., \& Gotham, H. J. (1998). Determinants of exercise among children. II. A longitudinal analysis. American Journal of Preventive Medicine, 27, 470-477. http://dx.doi.org/10.1006/pmed.1998.0307 
Eccles, J. S., Adler, T. F., Futterman, R., Goff, S. B., Kaczala, C. M., Meece, J. L., \& Midgley, C. (1983). Expectancies, values, and academic behaviors. In J. T. Spence (Ed.), Achievement and achievement motivation San Francisco (pp. 75-146). CA: Freeman.

Fredricks, J. A., \& Eccles, J. S. (2004). Parental influences on youth involvement in sports. In M. R. Weiss (Ed.), Developmental sport and exercise psychology (pp. 145-164). Morgantown, WV: Fitness Information Technology.

Freedson, P., \& Evenson, S. (1991). Familial aggregation in physical activity. Research Quarterly for Exercise \& Sport, 62, 384-389. http://dx.doi.org/10.1080/02701367.1991.10607538

Gallahue, D. L. (1996). Developmental physical education for today's children (3rd ed.). Madison: Brown \& Benchmark.

Godin, G., \& Shephard, R. J. (1986). Psychosocial factors influencing intentions to exercise of young students from grades 7 to 9. Research Quarterly for Exercise \& Sport, 57, 41-52. http://dx.doi.org/10.2466/pms.1986.62.2.511

Godin, G., Shephard, R. J., \& Colantonio, A. (1986). Children's perception of parental exercise: influence of sex and age. Percept Motor Skills, 62, 511-516. http://dx.doi.org/10.1080/02701367.1986.10605387

Gottlieb, N. H., \& Chen, M. (1985). Sociocultural correlates of childhood sporting activities: their implications for heart health. Social Science \& Medicine, 21, 533-539. http://dx.doi.org/10.1016/0277-9536(85)90037-1

Greendorfer, S. L. (1992). Sport socialization. In T. S. Horn (Ed.), Advances in sport psychology (pp. 201-218). Champaign IL: Human Kinetics.

Jacobs, J. E., \& Eccles, J. S. (1992). The impact of mothers' gender role stereotypic beliefs on mothers' and children's ability perceptions. Journal of Personality and Social Psychology, 63, 932-944. http://dx.doi.org/10.1037/0022-3514.63.6.932

Loucaides, C. A., Chedzoy, S. M., Bennett, N., \& Walshe, K. (2004). Correlates of physical activity in a Cypriot sample of sixth-grade children. Pediatric Exercise Science, 16, 25-36.

Mackett, R. L., \& Paskins, J. (2008). Children's physical activity: The contribution of playing and walking. Child Society, 22, 345-357. http://dx.doi.org/10.1111/j.1099-0860.2007.00113.x

McGrath, A. P., \& Repetti, R. L. (2000). Mothers' and fathers' attitudes toward their children's academic performance and children's perceptions of their academic competence. Pediatric Exercise Science, 5, 224-233.

Moore, L. L., Lombardi, D., White, M. J., Campbell, J. L., Oliveria, S. A., \& Ellison, R. C. (1991). Influence of parents' physical activity levels on young children. Journal of Pediatrics, 118, 215-219. http://dx.doi.org/10.1016/S0022-3476(05)80485-8

Perusse, L., Leblanc, C., \& Bouchard, C. (1988). Familial resemblance in lifestyle components: results from the Canada Fitness Survey. Canadian Journal of Public Health, 79, 201-205.

Perusse, L., Tremblay, A., Leblanc, C., \& Bouchard, C. (1989). Genetic and environmental influences on level of habitual physical activity and exercise participation. American Journal of Epidemiology, 129, 1012-1022.

Prochaska, J. J., Rodgers, M. W., \& Sallis, J. F. (2002). Association of parent and peer support with adolescent physical activity. Research Quarterly for Exercise \& Sport, 73, 206-210. http://dx.doi.org/10.1080/02701367.2002.10609010

Sallis, J. F., Prochaska, J. J., \& Taylor, W. C. (2000). A review of correlates of physical activity of children and adolescents. Medicine \& Science in Sports \& Exercise, 32, 963-975. http://dx.doi.org/10.1097/00005768-200005000-00014

Simonen, R. L., Perusse, L., Rankinen, T., Rice, T., Rao, D. C., \& Bouchard, C. (2002). Familial aggregation of physical activity levels in the Quebec family study. Medicine \& Science in Sports \& Exercise, 34, 1137-1142. http://dx.doi.org/10.1097/00005768-200207000-00014

Stipek, D. J., Recchia, S., \& Mc Clintic, S. (1992). Self-evaluation in young children. Monographs of the Society for Research in Child Development, 5, 71-84.

Taylor, W. C., Baranowski, T., \& Sallis, J. F. (1994). Family determinants of childhood physical activity: a social cognitive model. In: Dishman RK, ed. Advances in exercise adherence (pp. 319-342). Champaign IL: Human Kinetics. 
Trost, S. G., Pate, R. R., Saunders, R., Ward, D. S., Dowda, M., \& Felton, G. (1997). A prospective study of the determinants of physical activity in rural fifth-grade children. American Journal of Preventive Medicine, 26, 257-263. http://dx.doi.org/10.1006/pmed.1996.0137

Trost, S. G., Sallis, J. F., Pate, R. R., Freedson, P. S., Taylor, W. C., \& Dowda, M. (2003). Evaluating a Model of Parental Influence on Youth Physical Activity. American Journal of Preventive Medicine, $25,4$. http://dx.doi.org/10.1016/S0749-3797(03)00217-4

Welk, G. J., \& Schaben, J. A. (2004). Psychosocial correlates of physical activity in children: A study of relationships when children have similar opportunities to be active. Measurement in Physical Education and Exercise Science, 8(2), 63-81. http://dx.doi.org/10.1207/s15327841mpee0802_2

Zakarian, J. M., Hovell, M. F., Hofstetter, C. R., Sallis, J. F., \& Keating, K. J. (1994). Correlates of vigorous exercise in a predominantly low SES and minority high school population. American Journal of Preventive Medicine, 23, 314-321. http://dx.doi.org/10.1006/pmed.1994.1044

\section{Copyrights}

Copyright for this article is retained by the author(s), with first publication rights granted to the journal.

This is an open-access article distributed under the terms and conditions of the Creative Commons Attribution license (http://creativecommons.org/licenses/by/3.0/). 